single wards intended for the segregation especially of puerperal patients. This pavilion is beyond the main hospital out in the garden, having a separate kitchen, ridge ventilation, and every special appliance to secure sanicæmic conditions. Strange to say, however, I found at the time of my visit not one patient in it, and this for a reason much stranger still, - -septicæmia had occurred in it to such an extent that it had been necessary for some time past to discontinue the use of the ward altogether. A pavilion ward, which in every particular is as a surgical ward unequalled in New York, and unsurpassed anywhere, is to be found at the Roosevelt Hospital. This also is of one storey, and in height, width, light, and decoration is perfection. Though completely removed from the main building so far as necessities of excommunication can require, the central kitchens, laundry, heating shafts, and ventilating shafts of the entire establishment are in direct communication with it ; all the benefits with none of the evils of a large and wellappointed hospital are thus secured in this ward in an exceptional degree. In the ventilation of this ward one point upon which I have always insisted is carried out. While in summer it can be made direct and intermediate by window and by double ridge, in winter all the fresh air is warm air, yet pure, the exit being by aspiration through a superheated shaft. This principle applied to each basin in the waterclosets secures an absence of odour it would be difficult to surpass. At the Woman's Hospital alone, however, have wards been erected as in Boston, with the express purpose of being burnt down or otherwise completely destroyed within a limited period. In the garden of this hospital there have been erected, some distance apart, several two-roomed wooden cottages. One room is the kitchen, the other an operating and bed-room. In these cottages exclusively the ovariotomies of this hospital are performed. Each cottage is occupied by one patient only at a time, and she stays undisturbed in the room where she was operated upon until it is unquestionably safe and expedient for her to be transferred to a general ward. On the slightest suspicion of contamination of one of these cottages it can be burnt without any loss to be mentioned, or it can be wheeled away intact, and be sold at half its cost for other uses. These truly cottage hospitals, and they alone, amongst public institutions, secure a segregation which is absolute. They imply, of course, special nurses and other extra expenses, which, if the principle be groundless, are nnwarrantable. If, however, but in a fractional part the principle be correct, he would be a most unchristian economist who should denounce the extra cost per life as extravagance or waste.

A Hospital Solarium.-As yet to the New York Hospital alone, of all the other hospitals in this city, and I believe in this country, belongs the credit of this bright redeeming feature in the always sad and depressing life of the hospital patient. This hospital has not only set the first example of having all its cooking and laundry work done at the top of the house but beyond all sight, sound, or smell of anything disagreeable it has utilised a part of its roof as a solarium. This solarium, which is directly accessible by the lifts, is a large greenhouse, which combines the further attractions of an aquarium, herbarium, aviary, museum, art gallery, library, reading room, and drawing room. In accordance with the prime objects in its construction, it secures, all day long, all the sunshine the sun pleases to give, minus the external cold; in summer all the breeze which only such an elevation can receive, while at all times the bay, the harbour, the Hudson river, and the mountains beyond present at one view a scene most bright, varied, and exhilarating. The Bigolow post-mortem table is another point in this hospital not unworthy of notice. This table, like most others of its class, dips towards a centre grating, but by elaborate arrangements beneath this grating and within its central and single leg, are found not only provision for drainage, but for ventilation. On the principle of aspiration, a continual air current downwards through the table leg is said to be obtained of sufficient volume and force to carry away without all oflensive emanation during autopsies. I have had no opportunity of personally observing its efficacy, but with this and with the original table of my friend, Dr. Bigelow, in Boston, considerable satisfaction is expressed. For convenience for the operator and thoroughness of drainage, a rim at its edge, and convergent groovings of its surface, after the mamer of the corresponding table in the Allgemeine Krankenhaus in Vienna, would seem to me not undesirable. This New York hospital is exactly the antithesis in architectural design of the new handsome wide-spreading hospital at Chicago. Here in this bijou establisbment can be seen in fewer minutes than in any other I know a larger number of the best points in modern hospital construction.

The Manhattan Eye and Ear Hospital is a crowning monu. ment to its originator, Dr. C. R. Agnew, and to his present colleagues. It is situated in a neighbourhood as fashionable as is that of St. George's in London, and in the descriptive account is announced the very sensible, but very unAmerican, fact that in addition to all the usual appliances for heating and ventilation nearly every ward and room has a fireplace in it, in which particular this hospital is different from and beyond any other $T$ know of in this city.

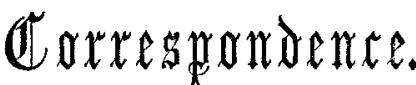 \\ "Audi alteram partem."}

\section{THE "EIRA" ARCTIC EXPEDITION.}

\section{To the Eatitor of THE LANCET.}

SrR,-It has been suggested by Dr. Buzzard and others that it would be interesting to know what kind of vegetables were saved from the Eira, and in what manner they were preserved and cooked.

1st. Potatoes. - Of these we had 150 tins, each containing $6 \mathrm{lb}$. of whole potatoes, which had been peeled, then half boiled and put into tins; these potatoes were cut up in small pieces and boiled with the meat for three or four hours. Messrs. Ritchie and Co., of Peterhead, had preserved them by Mr. Leigh-Smith's special instructions.

2nd. Carrots.-Also preserved in $6 \mathrm{lb}$. tins, and partly boiled. We used them in the same manner as the potatoes, and saved about 180 tins.

3rd. Edward's Dried Potatoes. -Of these we had about 150 lb. We used them twice a week, putting, as a rule $2 \mathrm{lb}$. into the dinner pot. These thickened the soup wonderfully.

4th. Dutch Vegetables. - Of these I cannot speak too highly. We, unfortunately, only saved thirty tins, containing about $10 \mathrm{lb}$. in each; some were potatoes and carrots, others potatoes and beans, others potatoes and peas. The Dutch preserve every kind of vegetable in these long tins, always mixing a good quantity of fat with them.

5th. - We had several small $1 \mathrm{lb}$. tins of peas, beans turnips, macedoine of vegetables, \&c., which were used occasionally when a little extra was wanted to celebrate any special occasion.-I am, Sir, yours truly,

Boundary-road, South Hampstead, N.W. W. H. NEALE, M.B., B.S.

\section{SCURVY.}

\section{To the Editor of THE LANCET.}

SIR, -I was struck by two independent observations which occurred in your columns last week with regard to the etiology of scurvy, both tending to controvert the generally received opinion that the exclusive cause of that disease is the prolonged and complete withdrawal of succulent vege tables from the dietary of those affected.

Thus Mr. Neale, of the Eira Arctic Expedition, says : "I do not think that spirit or limejuice is of much use as an anti. scorbutic; for if you live on the flesh of the country, even, I believe, without vegetables, you will run very little risk o scurvy." Dr. Lucas writes: "In the case of the semisavage hill tribes of Afghanistan and Beluchistan their food contains a large amonnt of meat, and is altogether devoid of vegetables. The singular immunity from scurvy of these races has struck me as a remarkable physiological circumstance, which should make us pause before accepting the vegetable doctrine in relation to scurvy." These observa tions do not stand alone. Arctic voyagers have long pointed out the antiscorbutic properties of fresh meat, and Baron Larrey, with regard to hot climates, arrived at the same conclusion in the Egyptian expedition under Bonaparte, at the end of last century.

The question now arises, How is it that tropical and arctic experience is at variance with that acquired in Europe? The only explanation that occurs to me is the different circumstances under which the meat is eaten. As is well known, the reaction of freshly killed meat is alkaline, 